\title{
SUPPRESSION OF MANGANESE SUPEROXIDE DISMUTASE ACTIVITY IN ROTENONE-TREATED HUMAN GLIOBLASTOMA T98G CELLS REDUCES CELL VIABILITY
}

\author{
SEPTELIA INAWATI WANANDI ${ }^{*}$, NOVI SILVIA HARDIANY ${ }^{1}$, NURJATI CHAIRANI SIREGAR ${ }^{2}$, MOHAMAD SADIKIN ${ }^{1}$ \\ ${ }^{1}$ Department of Biochemistry and Molecular Biology, Faculty of Medicine, Universitas Indonesia, Jakarta, Indonesia. ${ }^{2}$ Department of \\ Anatomic Pathology, Faculty of Medicine, Universitas Indonesia, Jakarta, Indonesia. Email: septelia@gmail.com/septelia.inawati@ui.ac.id
}

Received:05 July 2017, Revised and Accepted: 23 September 2017

ABSTRACT

Objective: Glioma is the most common human primary brain tumor which is highly resistant to oxidative stress-based anticancer. The aim of this study was to analyze the effect of rotenone-induced reactive oxygen species (ROS) on the modulation of manganese superoxide dismutase (MnSOD) expression and cell viability in human glioblastoma (GBM) T98G cells.

Methods: In this in vitro experimental study, T98G cells were treated with high-dose rotenone (0.5, 5, and $50 \mu \mathrm{M}$, respectively). Following rotenone treatment and intracellular ROS, both peroxide and superoxide radicals were determined. Moreover, we analyzed MnSOD mRNA expression, protein, and specific activity, as well as cell survival including viability, proliferation, apoptosis, and mitochondrial structure.

Results: High-dose rotenone treatment of T98G cells significantly increased intracellular ROS and MnSOD mRNA, but its protein and specific activity definitely decreased. The treatment also led to a reduction of cell viability, enhancement of apoptosis, and disruption of mitochondrial integrity.

Conclusion: Overproduction of ROS in rotenone-treated human GBM T98G cells could suppress the MnSOD protein level and activity even though mRNA synthesis has been increased. This modulation led to reduced survival of T98G cells through induction of cell death rather than inhibition of cell proliferation.

Keywords: Cell viability, Glioblastoma multiforme, Manganese superoxide dismutase, Rotenone.

(C) 2018 The Authors. Published by Innovare Academic Sciences Pvt Ltd. This is an open access article under the CC BY license (http://creativecommons. org/licenses/by/4. 0/) DOI: http://dx.doi.org/10.22159/ajpcr.2018.v11i1.19777

\section{INTRODUCTION}

Glioma is the most common human primary brain tumor which arises from glial cells [1]. Nowadays, the use of conventional treatments such as chemotherapy and radiation does not significantly enhance the life expectancy of glioma patients, particularly those with high-grade malignant (the WHO Grade IV) multiforme glioblastoma (GBM) patients, which is highly resistant to therapy [2]. Combinatorial treatment strategy has been reported to have improved the chemotherapeutic delivery to tumor cells in the brain $[3,4]$. Nevertheless, accumulating evidence suggests that dysregulation of cell cycle and apoptosis could lead to radiotherapy resistance [5]. A plausible mechanism for this resistance might involve high antioxidant status in tumor cells which could affect cell survival in response to radiation-induced oxidative stress [6].

Manganese superoxide dismutase (MnSOD) is a major cellular antioxidant located in the mitochondrial matrix. This enzyme catalyzes the reactive superoxide anion into hydrogen peroxide which will be later eliminated by catalase or peroxidase. The previous studies have reported that the upregulation of MnSOD expression could inhibit the phenotype of various cancer cells, suggesting that MnSOD is a tumor suppressor [7-10]. However, this assumption is still controversial, since it has been demonstrated that MnSOD was overexpressed in several human cancers including GBM [11]. Furthermore, MnSOD has been reported to have an important role on tumor cell growth and proliferation in ovarian cancer through regulation of superoxide level [12]. Our recent study has confirmed that MnSOD mRNA expression and specific activity in human glioma cells isolated from clinical specimens were higher than those in normal brain cells. In addition, the oxidative stress biomarkers, i.e., malondialdehyde, carbonyl compounds and 8-OHdG, were notably enhanced [8]. Interestingly, when these cells were categorized based on tumor grade, we found that the high-grade malignant glioma cells expressed MnSOD mRNA at higher levels compared to the low-grade but had lower specific activity.

The differential between MnSOD mRNA level and specific activity in high-grade glioma prompted a line of inquiry to investigate whether this was associated with reactive oxygen species (ROS) levels in these cells. Therefore, the aim of this study was to analyze the effect of rotenoneinduced ROS in human GBM on the modulation of MnSOD expression and its association with cell viability. High-dose rotenone was applied to human GBM T98G cells to induce overproduction of intracellular ROS, which is an expected consequence of radiotherapy. Rotenone is an inhibitor of mitochondrial complex I electron transport chain, which increases the mitochondrial ROS generation, particularly superoxide radicals, and leads to cytotoxicity [13-15]. It has also been reported that this toxin could be used as an anticancer agent [15]. Finally, this study is also projected to elaborate on the role of MnSOD in high malignant GBM patients who are resistant to radiotherapy. The outcome of this study has the potential for improving the management of GBM.

\section{MATERIAL AND METHODS}

\section{Cell culture}

The human GBM cell line T98G (kindly provided by Prof. Alexander Brehm from Institutfuer Molekularbiology und Tumorforschung Philipps Universität Marburg, Germany; ATCC No. CRL-1690 ${ }^{\mathrm{TM}}$ ) was maintained in high glucose DMEM containing $10 \%$ of heatinactivated fetal bovine serum, $3.7 \mathrm{~g} / \mathrm{L}$ of sodium bicarbonate, $1 \%$ Streptomycin - Penicillin, and $1 \%$ amphotericin $\mathrm{B}$ at $37^{\circ} \mathrm{C}$ in a humidified atmosphere of $95 \%$ air and $5 \% \mathrm{CO}_{2}$. The cells were subcultured with $0.25 \%$ trypsin and $1 \%$ ethylenediaminetetraacetic acid (EDTA) whenever the culture reached confluence. A subcultivation 
ratio was 1:2-1:5. Cells were utilized for analysis within 15 passages since it has been demonstrated that antioxidant enzyme levels in tumor cells subcultured up to 50 passages did not change [8].

\section{Rotenone treatment}

Rotenone powder (Sigma Aldrich, USA) was first dissolved in dimethyl sulfoxide (DMSO) to obtain $10 \mathrm{mM}$ stock solution. One day before rotenone treatment, $5 \times 10^{4} \mathrm{~T} 98 \mathrm{G}$ cells were plated triplicate in a 24well plate and grown in the same medium without free serum. Cells were treated with various concentrations of rotenone and incubated for $6 \mathrm{~h}$, as described previously [12]. Negative controls were T98G cells without rotenone or DMSO treatment, as well as T98G cells treated with the same volume of vehicle DMSO used to dissolve rotenone. Rotenone treatment was repeated 3 times at different time points. After the treatment, cells were washed with phosphate-buffered saline (PBS), harvested and then centrifuged at $1000 \mathrm{rpm}$ for $5 \mathrm{~min}$. Finally, cells were counted and prepared either for the cell viability or proliferation analysis, as well as for the isolation of total RNA and protein, followed by the analysis of MnSOD mRNA expression, protein level, and specific activity, respectively.

\section{Determination of intracellular ROS level}

Intracellular ROS was measured at the level of hydrogen peroxide and superoxide anions. For peroxide level measurement, dichlorodihydrofluorescein diacetate (DCFH-DA) assay (Molecular Probes, USA) was performed based on the intracellular peroxidedependent oxidation of $2^{\prime}, 7^{\prime}$-(DCFH-DA to form the fluorescent compound 2',7'-dichlorofluorescein DCF, as described previously [16]. Dihydroethidium (DHE) (Invitrogen) assay could detect the presence of superoxide anion which enzymatically converts hydroethidine to ethidium. T98G cell pellets containing $2 \times 10^{4}$ cells were resuspended in PBS containing $20 \mu \mathrm{M}$ DCFH-DA or $20 \mu \mathrm{M}$ DHE and incubated for $30 \mathrm{~min}$ at $37^{\circ} \mathrm{C}[17,18]$. Cells were then rinsed with PBS (2 times) and centrifuged $1000 \mathrm{rpm}$ for $5 \mathrm{~min}$. Cell pellets were resuspended in $3 \mathrm{~mL}$ PBS. Fluorescence intensity was measured using the Microplate Fluorometer (Varioskan Flash ${ }^{\circledR}$, Thermo Scientific, Finland) at $485 \mathrm{~nm}$ and $488 \mathrm{~nm}$ excitation, as well as $530 \mathrm{~nm}$ and $585 \mathrm{~nm}$ emission for DCFH-DA and DHE assays, respectively.

\section{Analysis of cell viability}

T98G cell viability was determined using MTS assay according to the manufacturer's protocol (Cell Titer 96Non-Radioactive Cell Proliferation Assay kit ${ }^{\circ}$; Promega, USA). Briefly, ten thousand cells after rotenone treatment were washed with PBS and added with $20 \mu \mathrm{l}$ of MTS/PMS mixture (MTS:PMS=20:1) to each well and incubated for $1-4 \mathrm{~h}$ under standard conditions $\left(5 \% \mathrm{CO}_{2}\right.$ at $\left.37^{\circ} \mathrm{C}\right)$. The quantity of formazan product was measured using spectrophotometer at $490 \mathrm{~nm}$, and the absorbance was directly proportional to the number of living cells in culture.

\section{Analysis of cell proliferation}

T98G cell proliferation was analyzed using the Cell Proliferation ELISA, BrdU kit ${ }^{\circledR}$ (Roche, Germany) according to the manufacturer's protocol. After rotenone treatment, $2 \times 10^{4}$ cells in each 24 -well plate were labeled with $20 \mu \mathrm{L} /$ well of BrdU and incubated for $24 \mathrm{~h}$. The reaction product was quantified by measuring the absorbance at $490 \mathrm{~nm}$ using the Microplate Reader (Varioskan Flash ${ }^{\circledR}$, Thermo Scientific, Finland). The developed color and thereby the absorbance values directly correlated to the amount of DNA synthesis and hereby to the number of proliferating cells.

\section{Analysis of cell apoptosis}

Cell apoptosis was analyzed using terminal deoxynucleotidyltransferase (TdT) dUTP Nick-End Labeling (TUNEL) assay (In Situ Cell Death Detection kit $囚$, POD) according to the manufacturer's protocol. This assay has been designed to detect apoptotic cells that undergo extensive DNA fragmentation during the late stages of apoptosis. Fifty thousand T98G cells were plated in slide chamber one day before rotenone treatment. The counterstaining process was performed using methyl green solution, as described previously [19]. Cells were observed under light microscope (Nikon ECLIPSE 80i). Dark brown cells were identified as apoptotic cells and calculated using Image J cell counter software (NCBI).

\section{Analysis of MnSOD mRNA expression using real-time polymerase} chain reaction (RT-PCR)

Total RNA was isolated from harvested T98G cell culture using Tripure Isolation kit ${ }^{\circledR}$ (Roche) according to the manufacturer's protocol. The concentration of total RNA was determined using spectrophotometry at $260 \mathrm{~nm}$ wavelength. cDNA of MnSOD was synthesized from $200 \mathrm{ng}$ of total RNA samples and amplified using iScript one-step RT-PCR Kit with SYBR Green $\AA(B i o R a d)$, according to the manufacturer's protocol. $18 \mathrm{~S}$ rRNA was used as a reference gene. The amplification protocol was performed using primers for MnSOD or 18SrRNA gene, as described in our previous report [20]. Aquabidest was used as a nontemplate control to exclude the false-positive result. The level of mRNA expression in rotenone-treated or DMSO-treated cells was relatively determined using Livak formula and normalized to that in the cells without any treatment as a control.

\section{Analysis of MnSOD protein}

Total protein was isolated from harvested T98G cell culture using Tripure Isolation kit ${ }^{\circledR}$ (Roche) according to manufacturer's protocol. Total protein concentration in each sample was first measured using spectrophotometer at $280 \mathrm{~nm}$ wavelength and plotted to the bovine serum albumin standard curve. The human MnSOD standard stocksolution was reconstituted by adding the dilution buffer to obtain MnSOD concentration of $1600,800,400,200,100,50,25$, and $0 \mathrm{pg} / \mathrm{mL}$. MnSOD protein levels were determined using spectrophotometer at $450 \mathrm{~nm}$ and calculated using the concentration of standards provided in the kit and the total protein concentration in each sample.

\section{Analysis of the MnSOD enzyme-specific activity}

MnSOD enzyme activity was measured using xanthine oxidase inhibition assay (RanSOD® kit, Randox), as previously described [19]. To inhibit the $\mathrm{Cu} / \mathrm{ZnSOD}$, first, natrium cyanide $(5 \mathrm{mM})$ was added into each sample, and the mixture was incubated for $5 \mathrm{~min}$ in room temperature [21]. MnSOD enzyme activity was expressed as percentage (\%) inhibition of the samples plotted to the standard curve. The specific activity of MnSOD enzyme was calculated as enzyme activity (in Unit) per mg total protein.

\section{Analysis of transmission electron microscopy (TEM)}

The mitochondrial ultrastructure of T98G cells-treated rotenone was obtained by TEM. Cells were firstly fixed in $2.5 \%$ glutaraldehyde containing $3 \%$ sucrose in $0.1 \mathrm{M}$ sodium cacodylate buffer $(\mathrm{pH}$ 7.4) for $24 \mathrm{~h}$ at $4^{\circ} \mathrm{C}$, then in $2.5 \%$ glutaraldehyde containing $3 \%$ sucrose in $0.1 \mathrm{M}$ sodium cacodylate buffer ( $\mathrm{pH} 7.4)$ for $3 \mathrm{~h}$ at $4^{\circ} \mathrm{C}$, and finally in $2 \%$ osmium tetroxide and $2.5 \% \mathrm{~K}_{3} \mathrm{Fe}(\mathrm{CN})_{6}$ in $0.1 \mathrm{M}$ cacodylate buffer (pH 7.4) for $2 \mathrm{~h}$ at $4^{\circ} \mathrm{C}$ [22]. Afterward, samples were dehydrated in graded ethanol for $15 \mathrm{~min}$, embedded in Spurr's resin for $24 \mathrm{~h}$ at room temperature and examined under a JEOL 1010 transmission electron microscope.

\section{Statistical analysis}

Statistical analysis was performed using Student's t-test (for comparison between rotenone- and DMSO-treated cells) or Wilcoxon test (for comparison of non-parametric data). Data were presented as mean $\pm S E$, and $p$ values of $<0.05$ were considered as being statistically significant.

\section{RESULTS}

\section{Generation of intracellular ROS by rotenone in T98G cells}

To determine the optimal rotenone concentration which could induce the overaccumulation of both superoxide and peroxide radicals intracellular, T98G cells were first treated with various concentrations of rotenone $(0.5 \mu \mathrm{M}, 5 \mu \mathrm{M}$ and $50 \mu \mathrm{M})$ for $6 \mathrm{~h}$. Fig. 1 demonstrates that rotenone could induce the production of both superoxide radicals 
(measured using DHE) and hydrogen peroxide (measured using DCFHDA) in T98G cells. When compared with the DMSO-treated T98G cells, superoxide levels were considerably enhanced in T98G cells treated with rotenone at a concentration of $0,5 \mu \mathrm{M}(1.37$-fold, $\mathrm{p}<0.05)$ and gradually increased at the concentration of $5 \mu \mathrm{M}(1.56$-fold, $\mathrm{p}<0.05)$ and $50 \mu \mathrm{M}(1.97$-fold, $\mathrm{p}<0.01)$. In addition, we could demonstrate in this study that high-dose rotenone could also significantly increase the peroxide level (1.77-fold, $\mathrm{p}<0.01$ at $50 \mu \mathrm{M})$

\section{Effect of rotenone treatment on cell survival}

In this study, we investigated the effect of rotenone treatment on the survival of T98G cells. To analyze T98G cell viability following rotenone treatment, an MTS assay was performed. The result demonstrated that the viability of T98G cells treated with rotenone of either 5 or $50 \mu \mathrm{M}$ was lower Fig. ( $\sim 0.5$ or 0.7 -fold, $\mathrm{p}<0.05)$ than their counterparts treated with DMSO (Fig. 2a). These data were consistent with the superoxide level, revealing that superoxide radicals generated by rotenone were able to lessen T98G cell viability. To verify whether the decrease of T98G cell viability was triggered by the reduction of cell proliferation or induction of cell death, we performed BrdU assay for cell proliferation and TUNEL assay for cell apoptosis. The result demonstrated that T98G cells proliferation following rotenone treatment was slightly decreased $(\sim 0.9$-fold; $p>0.05)$ compared with the cells treated with DMSO (Fig. 2b).

In contrast to the result of cell proliferation, TUNEL assay in T98G cells treated with high-dose rotenone $(50 \mu \mathrm{M})$ detected a remarkable increase of dark brown cells $(\sim 1.6$-fold; $p<0.05)$ compared with the control (non-treated cells) and DMSO-treated cells, respectively (Fig. 3). This indicates that high-dose rotenone provoked cell apoptosis which was most likely caused by overproduction of both superoxide and peroxide radicals.

Effect of rotenone treatment on MnSOD expression

To determine whether high-dose rotenone was efficient in stimulating the antioxidant response against the overproduction of ROS, we assessed the expression of MnSOD - a major antioxidant enzyme located in mitochondria - by gathering its level of mRNA and protein expression as well as its specific activity levels. In Fig. $4 \mathrm{a}$ and b, we found that the

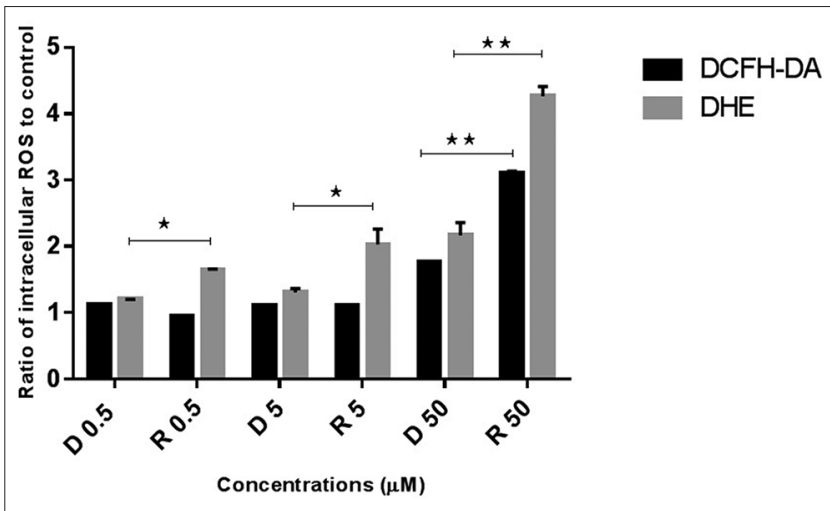

Fig. 1: Effect of various rotenone concentrations on the reactive oxygen species (ROS) production. T98G cells were treated either with various concentrations of rotenone $(0.5,5$, and $50 \mu \mathrm{M}$, respectively) in dimethyl sulfoxide (DMSO) or with the same volume of DMSO (as vehicle) used for dissolving rotenone. ROS levels were determined using DCFH-DA and DHE assay as described under "material and methods." Fluorescence intensity of oxidized dichloro-dihydro-fluorescein diacetate and dihydroethidium in treated cells was expressed as ratio to control (cells without any treatment). All values are means, $n=3$. Student's t-test showed significant differences at $*(p<0.05)$ and ** $(p<0.01)$ compared to those of DMSO-treated cells. D: DMSO, $\mathrm{R}$ : Rotenone relative expression level of MnSOD mRNA in $50 \mu \mathrm{M}$ rotenone-treated T98G cells was significantly upregulated $(\sim 3.8$-fold; $p<0.01)$. In contrast to the mRNA expression, high-dose rotenone led to a remarkable decrease in the protein levels $(\sim 6.2$-fold lower; $p<0.01)$ and specific activity of MnSOD in T98G cells ( $\sim 1.4$-fold; $\mathrm{p}<0.05)$. This revealed that high-dose rotenone modulated the MnSOD expression in T98G cells, leading to the modulations in its mRNA, protein, and activity levels.

Effect of rotenone treatment on the mitochondrial structure To evaluate whether rotenone - an inhibitor of the mitochondrial transport electron chain - could disrupt the mitochondrial integrity of T98G cells, we observed the ultrastructure of mitochondria using TEM. The result illustrated that mitochondria of T98G cells treated with highdose rotenone were swollen and exhibited irregular cristae with loss of lipid bilayer membrane (Fig. 5c), in contrast to the non-treated (Fig. 5a) and DMSO-treated cells (Fig. 5b), respectively. In the T98G cells treated with DMSO solely, although the mitochondria also tended to be swelling and irregular, the lipid bilayer membrane and cristae remained intact indicating that the mitochondria integrity was maintained (Fig. 5b). This observation demonstrated that rotenone treatment in T98G cells could lead to mitochondrial damage and cell death.

\section{DISCUSSION}

Rotenone is an herbal pesticide that blocks electrons flow from complex I to coenzyme $Q$ of the electron transport chain in mitochondria [23]. As a lipophilic molecule, rotenone can freely penetrate through the cell

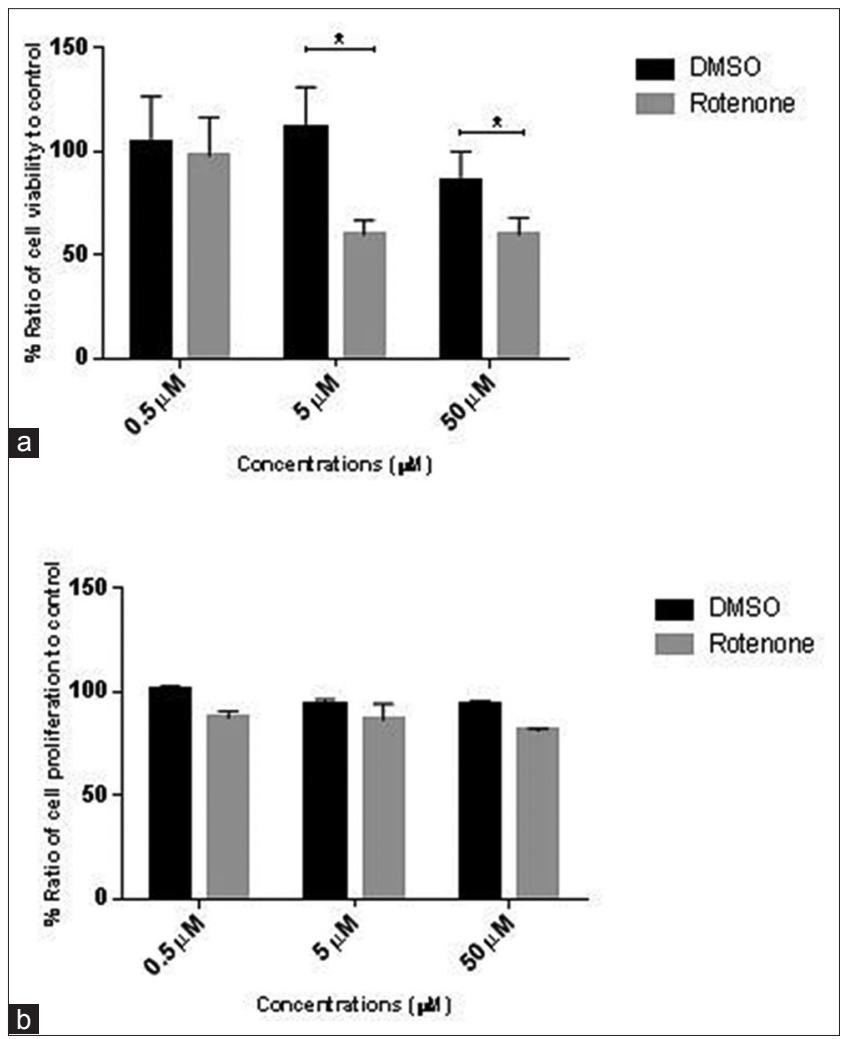

Fig. 2: Effect of rotenone treatment on cell viability (a) and proliferation (b) on various concentration. T98G cells $\left(1 \times 10^{5}\right.$ cells $)$ were first treated with $0.5 \mu \mathrm{M}, 5 \mu \mathrm{M}$, and $50 \mu \mathrm{M}$ rotenone in dimethyl sulfoxide (DMSO) or with DMSO (as vehicle) solely. Then, a MTS assay was performed for the cell viability and BrdU assay for cell proliferation, respectively, as described under the aforementioned material and methods section. Data were calculated as a percentage of the control (cells without any treatment). All values are means \pm standard error, $n=9$. Student's t-test showed significant differences at $*(p<0.05)$ compared to the cells treated with DMSO 


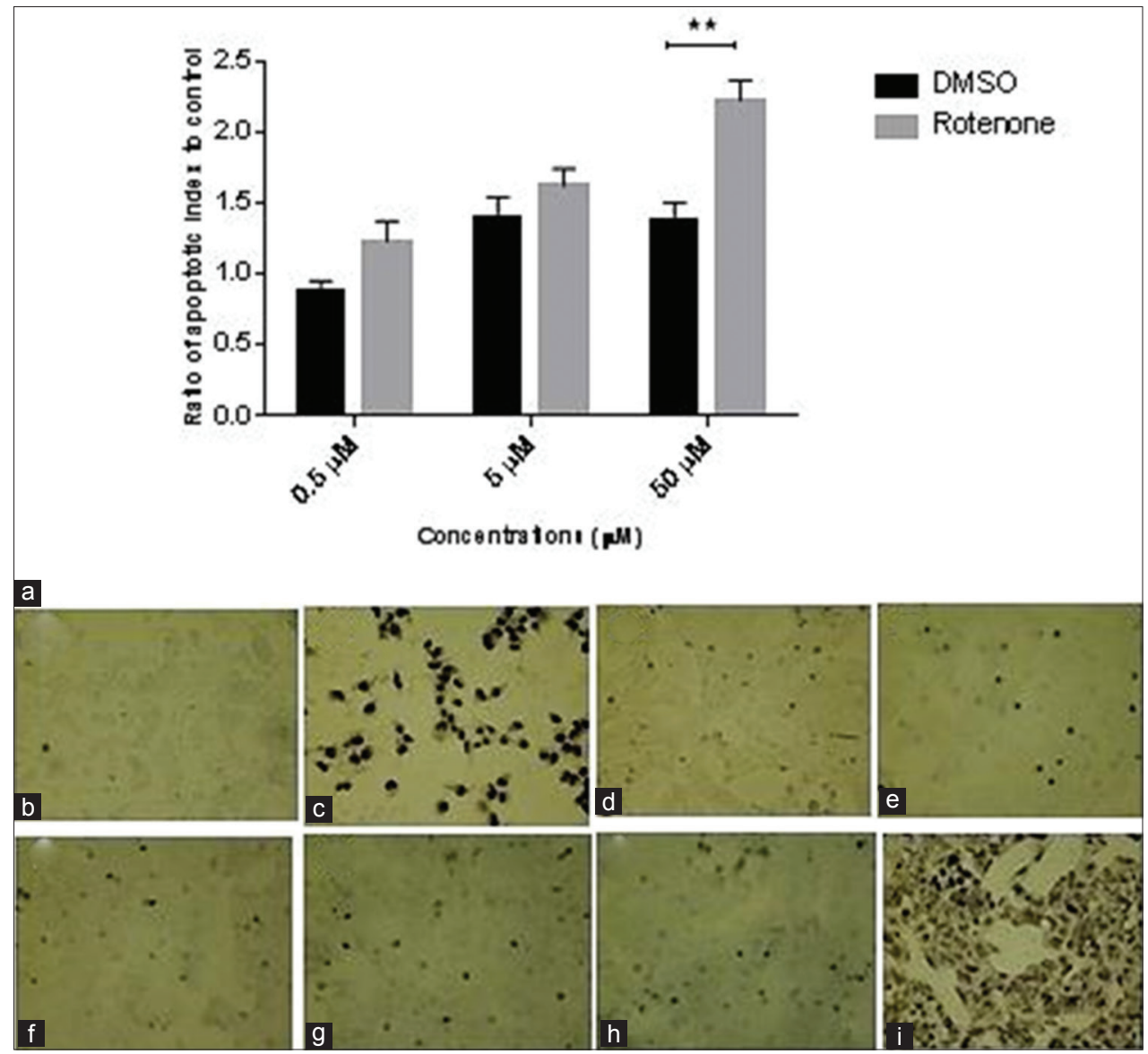

Fig. 3: Effect of rotenone treatment on DNA fragmentation. (a) T98G cells $\left(1 \times 10^{5}\right.$ cells $)$ were first treated with various concentrations of rotenone in dimethyl sulfoxide (DMSO) and with an equivalent volume of DMSO (as vehicle), respectively. Subsequently, TUNEL assays were performed as described under the material and methods sectopm. Data were calculated as a percentage of control (cells without any treatment). All values are means \pm standard error, $n=9$. Student's t-test showed significant differences at $* *(p<0.01)$ compared to the cells treated with DMSO. (b-i) micrographs of TUNEL-stained T98G treated with rotenone. Cells were observed under inverted microscope with $\times \mathbf{2 0 0}$ magnification. (b) Negative control (cells without treatment); (c) positive control (cells + DNAse); (d) cells + DMSO for $0.5 \mu M$ rotenone (vehicle); (e) cells + $0.5 \mu \mathrm{M}$ rotenone; (f) cells + DMSO for $5 \mu \mathrm{M}$ rotenone (vehicle); (g) cells + $5 \mu$ M rotenone; (h) Cells + DMSO for $50 \mu \mathrm{M}$ rotenone (vehicle); (i) cells $+50 \mu \mathrm{M}$ rotenone. Apoptotic cells exhibiting DNA fragmentation were stained dark brown. Slides were counter-stained with methyl green to identify background TUNEL-negative cells

membrane into the cytoplasm and mitochondria and easily transfer across the blood-brain barrier [23]. It has been reported that rotenone treatment could induce free radical generation, leading to oxidative damages, such as mitochondrial dysfunction, ubiquitin-dependent proteasome dysfunction and endoplasmic reticulum stress, as well as cell death $[25,26]$. In the present study, we confirmed that rotenone induced the accumulation of mitochondrial ROS, as reported previously $[25,26]$. Although superoxides were the main ROS generated as a result of mitochondrial complex I inhibition, here, we demonstrated that highdose rotenone could stimulate the substantial production of peroxides as well. This might be due to the increased conversion of superoxides into hydrogen peroxides catalyzed by MnSOD in mitochondria.

The rotenone treatment of T98G cells performed in this study can serve as a model for oxidative stress induction during radiotherapy for glioma patients. Radiotherapy induces ROS production in tumor cells, either to facilitate tumor cell death through a process of apoptosis or to suppress the tumor growth through an inhibition of cell proliferation. Here, we found that rotenone concentration of 5 or $50 \mu \mathrm{M}$ suppressed the viability of T98G cells, indicating high ROS levels [27]. The assessment of cell viability should be considered to be one of the primary criteria for apoptosis [28]. Through the use of a TUNEL assay, we observe an increase in DNA fragmentation which indicated cell death induced by chromatin dysfunction in T98G cells after high-dose rotenone treatment. Therefore, we suggested that the decline of cell viability following rotenone treatment is more likely due to the stimulation of cell apoptosis rather than the inhibition of cell proliferation since the BrdU assay performed in this study has indicated no significant decrease of T98G cell proliferation. Comparable results have also been reported by other previous studies, suggesting that rotenone does not affect the S-phase of cell proliferation [29,30]. Meanwhile, low-dose rotenone treatment $(0.5-1 \mu \mathrm{M})$ for $18 \mathrm{~h}$ has been demonstrated to enhance apoptosis in HL-60 cells through cytochrome c release, caspase- 3 activation, and DNA breakdown [26].

However, it should be considered that ROS-mediated DNA fragmentation presented by the TUNEL assay could be detected not only merely in apoptosis but also in the necrosis process [31]. In addition, using a TEM assay, we could observe the mitochondrial swelling with loss of cristae structure and loss of membrane integrity in the cells treated with highdose rotenone, which is more likely an indicator of necrosis rather than apoptotic cell death, as described previously [32,33]. It has been suggested that an inhibitor of the mitochondrial electron transport chain such as rotenone-induced necrosis rather than apoptosis [33]. This effect was surely unexpected and should be taken into account during the management of cancer therapies in the future. 


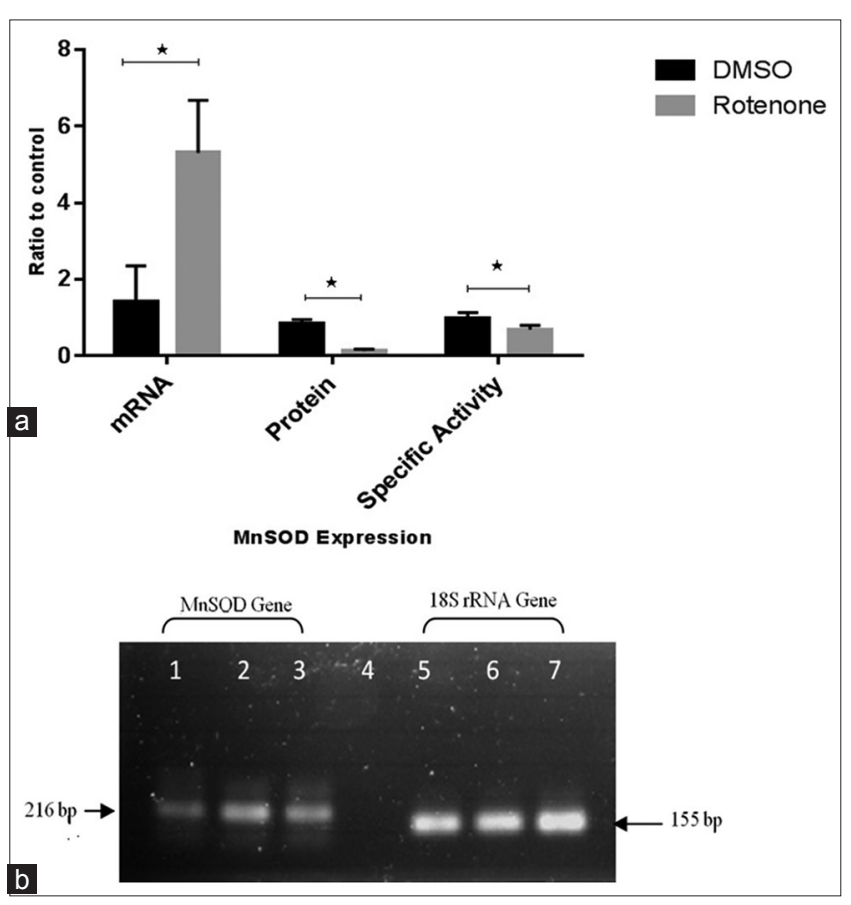

Fig. 4: Analysis of mRNA relative expression, protein, and specific activity of manganese superoxide dismutase (MnSOD).T98G cells treated by $50 \mu \mathrm{M}$ rotenone and dimethyl sulfoxide (DMSO) (vehicle), respectively. Total RNA was extracted from the cells, and cDNA product was amplified using real-time polymerase chain reaction methods, as described under the material and methods section. (a) Expression level was relatively calculated and normalized with respect to the control group (cells without treatment). All values are means \pm standard error (SE), $n=9$. Significant differences at $*(p<0.05)$. Total protein was extracted from the cells as described under the material and methods section. MnSOD protein level was determined using enzymelinked immunosorbent assay (NWLSSTM MnSOD ELISA kit). MnSOD-specific activity was measured using RanSOD $®$ kit

(Randox). All values are means $\pm S E, n=9$. Student's $t$-test showed significant differences at $*(p<0.05)$. (b) Gel electrophoresis agarose $1 \%$ of cDNA products. Lane 1, 5 : Cells without treatment, lane 2, 6: Cells+rotenone, lane 3, 7: Cells+DMSO, lane 4: Non template control

To counterbalance the rotenone-induced ROS abundance in the cells, cellular antioxidants are also recruited to eliminate ROS. When there is an imbalance between the cellular antioxidant levels and ROS accumulation, it will induce a state of oxidative stress which inflicts various oxidative damage on essential macromolecules in the cells, such as lipid, protein, and DNA [34]. Therefore, we focused to analyze the response of rotenone induction on the expression of MnSOD, the major free radical scavenging enzyme in the mitochondrial matrix. MnSOD was initially thought to have tumor suppressor activity, but the recent studies have proved that the expression of this enzyme was upregulated in many cancers which suggest that it may play a role in increasing the invasive properties of tumor cells [12,35-38]. In primary GBM multiforme, upregulation of MnSOD gene expression has been suggested as a specific diagnostic marker through transcriptome analysis [39]. Several studies have proposed that MnSOD acts as an anti-apoptotic factor. Thus, upregulation of MnSOD gene expression could lead to ROS-based therapy resistance [40-42]. Indeed, our recent report has found that MnSOD mRNA synthesis was upregulated in high-grade GBM cells isolated from clinical specimens, but its protein and specific activity levels were lower compared to normal brain cells [7]. In contrast to those results, other previous study that used tissue microarray analysis has shown that MnSOD protein expression in ovarian carcinoma was significantly higher than in benign tumor and normal tissue [12].

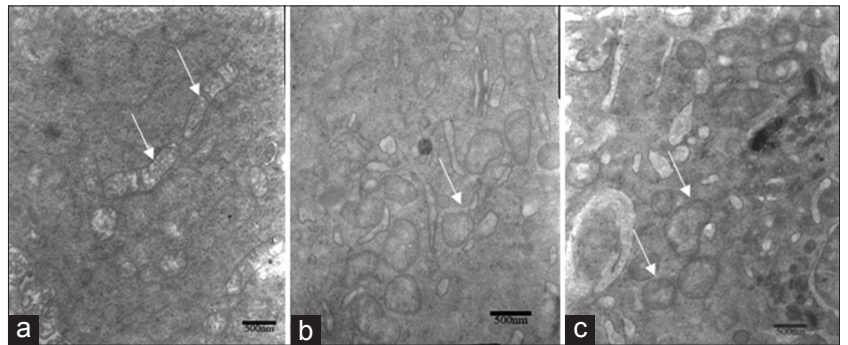

Fig. 5: The ultrastructure of mitochondria was evaluated by transmission electron microscopy. (a) Typical mitochondrial structure (white arrow) showing regular size and shape, as well as intact lipid bilayer membrane in T98G cells without treatment.

(b) Swollen mitochondria (white arrow) with irregular shape

and size. Lipid bilayer membrane was still visible in cells treated with dimethyl sulfoxide $50 \mu \mathrm{M}$ for $6 \mathrm{~h}$. (c) Various sizes of swollen mitochondria (white arrow) with irregular cristae in cells treated with rotenone $50 \mu \mathrm{M}$ for $6 \mathrm{~h}$. White arrows signed for mitochondria. Bars: $D=\mathbf{5 0 0} \mathbf{n m}$

Interestingly, the present study hinted that both the protein level and specific activity of MnSOD in the cells treated with high-dose rotenone were significantly lower than those in control cells, which contradicted findings in the previous reports $[12,26]$. In addition, we specifically employed the analysis of MnSOD enzyme-specific activity with a xanthine oxidase inhibition assay and inhibited $\mathrm{Cu} / \mathrm{ZnSOD}$ activity by adding natrium cyanide [20]. It should be noted that the rotenone dose optimized in this study was higher than the dosages used in the aforementioned studies and presuming that the overaccumulation of intracellular ROS may exceed the antioxidant capacity of MnSOD, which reduces the availability and activity of MnSOD. More interestingly, the present study revealed that high-dose rotenone $(50 \mu \mathrm{M})$ could modulate mRNA, protein, or specific activity levels of MnSOD in T98G cells. Although the synthesis of MnSOD mRNA has been upregulated, accumulation of intracellular ROS was elevated, as indicated by high superoxide and peroxide levels, which led to insufficient levels of active intracellular MnSOD enzyme. Thus, the imbalance between high ROS level and low activity of MnSOD found in the present study was due to high-dose rotenone-induced oxidative stress.

On the other hand, we should also consider the possibility that ubiquitin-proteasomal degradation of MnSOD protein is exaggerated by the high abundance of intrinsic ROS leading to mitochondrial dysfunction $[25,26]$. This assumption is supported by the TEM assay results in the present study demonstrating that the mitochondrial disruption in T98G cells is induced by high ROS levels. Alternatively, the discrepancy between high MnSOD mRNA and low protein or specific activity level might be associated with the dysregulation of MnSOD protein synthesis influenced by overproduction of ROS. The steady state of mRNA levels perceived using quantitative RT-PCR method is a cumulative result of several regulatory mechanisms, including transcription, RNA processing, and RNA stability, whereas the protein level and activity are predominantly influenced by translational and post-translational processing, as well as innate variations in stability. Several comparative transcriptomics and proteomics in mouse offer evidence that there is a low correlation between transcript and encoded protein levels $[43,44]$.

Here, we highlight the importance of the MnSOD gene expression analysis at the level of mRNA and protein, as well as enzyme activity. Unlike the previous report on ovarian cancer [12], our concomitant study has obtained that the suppression of MnSOD mRNA expression in T98G cells through siRNA transfection could reduce the protein level and enzyme activity and enhance superoxide radicals production, leading to cell death [45]. Hence, we evidently suggest that the impact of oxidative stress induced by high-dose rotenone is most likely associated with low MnSOD expression at the level of protein and enzyme activity. Increased 
MnSOD mRNA levels which resulted in the increased availability of MnSOD antioxidants might be the result of a cellular adaptive response to oxidative stress. It should be considered that the impact of rotenone on cell survival is not only limited through enhancing the amount of intracellular ROS, both superoxide and peroxide radicals, but also through the modulation of MnSOD gene expression.

Based on the results of this study, we could elucidate that the discrepancy between high MnSOD mRNA and low protein or specific activity levels in human high-grade glioma cells reported in our previous study might be due to oxidative damage triggered by excessive production of ROS, as demonstrated by the increase of protein carbonyls as a marker of protein oxidative damage in the high-grade compared to low-grade glioma and normal brain cells [7]. Nevertheless, in contrast to the present study, the rate of cell proliferation was higher, and the rate of apoptosis was lower in the high-grade compared to lowgrade glioma cells. It seems that the redox signaling pathway regulating cell viability was not similar to that observed in this study. It has been formerly reported that moderate ROS levels were able to induce cell proliferation through a redox signaling pathway, which contributed to tumor growth, whereas high ROS levels stimulated apoptosis [27]. Furthermore, in that study, we have demonstrated that cell survival of high-grade glioma from clinical specimens was strongly correlated with the MnSOD mRNA level [7]. Therefore, we presume that MnSOD gene expression might be responsible for the modulation of redox signaling mechanisms contributing to tumor cell survival in high-grade glioma cells, and further affecting tumor malignancy and ROS-based cancer therapy resistance.

\section{CONCLUSION}

Based on our findings, we conclude that overproduction of ROS in rotenone-treated human GBM T98G cells could suppress the MnSOD protein level and activity even though its mRNA synthesis has increased. This diminished cell survival rates through enhancement of cell death rather than inhibition of cell proliferation. Suppression of MnSOD protein level and activity might be beneficial for radiotherapy. However, the upregulation of MnSOD mRNA synthesis during ROS-based cancer therapy should be considered, since it would maintain the availability of MnSOD activity and may also reenhance cell viability and proliferation. Therefore, the suppression of MnSOD synthesis in glioma cells before radiotherapy could be proposed as a targeted therapy to treat radiation resistance of GBM.

\section{ACKNOWLEDGMENT}

This research was funded by Riset Unggulan Universitas Indonesia (RUUI) 2010. The authors would like to express our gratitude to Direktorat Riset dan Pengabdian Masyarakat Universitas Indonesia for supporting the research and also to Higher Education Network Ring Initiative for writing assistances.

\section{REFERENCES}

1. Schwartzbaum JA, Fisher JL, Aldape KD, Wrensch M. Epidemiology and molecular pathology of glioma. Nat Clin Pract Neurol 2006;2:494-503.

2. Goldlust SA, Turner GM, Goren JF, Gruber ML. Glioblastoma multiforme: Multidisciplinary care and advances in therapy. Hosp Physician 2008;39:9-22

3. Maji P, Chatterjee R, Choudhury BP, Chatterji U, Ganguly J. Enhanced p53-dependent growth inhibition of human glioblastoma cells by combinatorial treatment of temozolomide and novel purified natural carbohydrate of Pleurotus florida. Int J Pharm Pharm Sci 2017;9:189-93.

4. Khan YY, Suvarna V. Liposomes containing phytochemicals for cancer treatment-an update. Int J Curr Pharm Res 2017;9:20-4.

5. Krakstad C, Chekenya M. Survival signalling and apoptosis resistance in GBM: Opportunities for targeted therapeutics. Mol Cancer 2010;9:135

6. Lee HC, Kim DW, Jung KY, Park IC, Park MJ, Kim MS, et al. Increased expression of antioxidant enzymes in radioresistant variant from U251 human glioblastoma cell line. Int J Mol Med 2004;13:883-7.

7. Hardiany NS, Mulyawan W, Wanandi SI. Correlation between oxidative stress and tumor grade in glioma cells from patients in Jakarta. Med J Indones 2012;21:122-7.

8. Zhong W, Oberley LW, Oberley TD, St Clair DK. Suppression of the malignant phenotype of human glioma cells by overexpression of manganese SOD. Oncogene 1997;14:481-90.

9. Venkataraman S, Jiang X, Weydert C, Zhang Y, Zhang HJ, Goswami PC, et al. Manganese SOD overexpression inhibits the growth of androgenindependent prostate cancer cells. Oncogene 2005;24:77-89.

10. Mancini A, Borrelli A, Schiattarella A, Fasano S, Occhiello A, Pica A, et al. Tumor suppressive activity of a variant isoform of manganese SOD released by a human liposarcoma cell line. Int $\mathrm{J}$ Cancer 2006;119:932-43.

11. Järvelä S, Bragge $\mathrm{H}$, Paunu N, Järvelä T, Paljärvi L, Kalimo $\mathrm{H}$, et al. Antioxidant enzymes in oligodendroglial brain tumors: Association with proliferation, apoptotic activity and survival. J Neurooncol 2006;77:131-40.

12. Hu Y, Rosen DG, Zhou Y, Feng L, Yang G, Liu J, et al. Mitochondrial manganese-SOD expression in ovarian cancer: Role in cell proliferation and response to oxidative stress. J Biol Chem 2005;280:39485-92

13. Siddiqui MA, Saquib Q, Ahamed M, Ahmad J, Al-Khedhairy AA, Abou-Tarboush FM, et al. Effect of trans-resveratrol on rotenoneinduced cytotoxicity in human breast adenocarcinoma cells. Toxicol Int 2011;18:105-10.

14. Li J, Spletter ML, Johnson DA, Wright LS, Svendsen CN, Johnson JA. Rotenone-induced caspase 9/3-independent and -dependent cell death in undifferentiated and differentiated human neural stem cells. J Neurochem 2005;92:462-76.

15. Fang N, Casida JE. Anticancer action of cubé insecticide: Correlation for rotenoid constituents between inhibition of NADH:ubiquinone oxidoreductase and induced ornithine decarboxylase activities. Proc Natl Acad Sci U S A 1998;95:3380-4

16. Ansari R, Perween Q, Kumar G, Jayanand, Rai DV. Effect of butylated hydroxyanisole on hydrogen peroxide induced oxidative stress on cerebral glioma cell line. Asian J Pharm Clin Res 2014;7 Suppl 1:177-80.

17. Shim HY, Park JH, Paik HD, Nah SY, Kim DS, Han YS. Acacetininduced apoptosis of human breast cancer MCF-7 cells involves caspase cascade, mitochondria-mediated death signaling and SAPK/ JNK1/2-c-Jun activation. Mol Cells 2007;24:95-104.

18. Viola G, Salvador A, Vedaldi D, Fortunato E, Disarò S, Basso G, et al. Induction of apoptosis by photoexcited tetracyclic compounds derivatives of benzo[b]thiophenes and pyridines. J Photochem Photobiol B 2006;82:105-16.

19. Barathi S, Vardhini S, Chitra P, Arulselvi PI. Cytotoxic effect of juglone on human peripheral blood lymphocytes. Asian J Pharm Clin Res 2013:6:178-86.

20. Hardiany NS, Sadikin M, Wanandi SI. Gene expression of manganese SOD (MnSOD) in human glioma cells. Med J Indones 2010;19:21-5.

21. Epperly M, Bray J, Kraeger S, Zwacka R, Engelhardt J, Travis E, et al. Prevention of late effects of irradiation lung damage by manganese SOD gene therapy. Gene Ther 1998;5:196-208.

22. Davies HA. General preparation of material and staining of sections. In: Electron Microscopy Methods and Protocols Methods in Molecular Biology. Totowa: Humana Press; 2007. p. 1-11.

23. Ahmadi FA, Linseman DA, Grammatopoulos TN, Jones SM, Bouchard RJ, Freed CR, et al. The pesticide rotenone induces caspase3-mediated apoptosis in ventral mesencephalic dopaminergic neurons. J Neurochem 2003;87:914-21.

24. Jin J, Davis J, Zhu D, Kashima DT, Leroueil M, Pan C, et al. Identification of novel proteins affected by rotenone in mitochondria of dopaminergic cells. BMC Neurosci 2007;8:67.

25. Rohini D, Vijayalakshmi K. Sesamol antagonizes rotenone induced cell death in SH-SY5Y neuronal cells. Int J Pharm Pharm Sci 2016;8:72-7.

26. Li N, Ragheb K, Lawler G, Sturgis J, Rajwa B, Melendez JA, et al. Mitochondrial complex I inhibitor rotenone induces apoptosis through enhancing mitochondrial ROS production. J Biol Chem 2003;278:8516-25

27. Murrell GA, Francis MJ, Bromley L. Modulation of fibroblast proliferation by oxygen free radicals. Biochem J 1990;265:659-65.

28. Bai L, Wang J, Yin XM, Dong Z. Analysis of apoptosis. In: Essentials of Apoptosis. Totowa, New Jersey: Humana Press; 2003. p. 239-50.

29. Gonçalves AP, Máximo V, Lima J, Singh KK, Soares P, Videira A. Involvement of $\mathrm{p} 53$ in cell death following cell cycle arrest and mitotic catastrophe induced by rotenone. Biochim Biophys Acta 2011;1813:492-9.

30. Wang XJ, Xu JX. Possible involvement of $\mathrm{Ca}^{2+}$ signaling in 
rotenone-induced apoptosis in human neuroblastoma SH-SY5Y cells. Neurosci Lett 2005;376:127-32.

31. Higuchi Y. Chromosomal DNA fragmentation in apoptosis and necrosis induced by oxidative stress. Biochem Pharmacol 2003;66:1527-35.

32. Krysko DV, Vanden Berghe T, D'Herde K, Vandenabeele P. Apoptosis and necrosis: Detection, discrimination and phagocytosis. Methods 2008;44:205-21.

33. Shimizu S, Eguchi Y, Kamiike W, Waguri S, Uchiyama Y, Matsuda H, et al. Retardation of chemical hypoxia-induced necrotic cell death by Bcl-2 and ICE inhibitors: Possible involvement of common mediators in apoptotic and necrotic signal transductions. Oncogene 1996; $12: 2045-50$.

34. Halliwell B, Gutteridge JM, editors. Cellular responses to oxidative stress: Adaptation, damage, repair, senescence and death. In: Free Radicals in Biology and Medicine. $4^{\text {th }}$ ed. New York: Oxford University Press; 2007. p. 187-267.

35. Ria F, Landriscina M, Remiddi F, Rosselli R, Iacoangeli M, Scerrati M, et al. The level of manganese SOD content is an independent prognostic factor for glioblastoma. Biological mechanisms and clinical implications. Br J Cancer 2001;84:529-34

36. Kim JJ, Chae SW, Hur GC, Cho SJ, Kim MK, Choi J, et al. Manganese SOD expression correlates with a poor prognosis in gastric cancer. Pathobiology 2002-2003;70:353-60.

37. Kattan Z, Minig V, Leroy P, Dauça M, Becuwe P. Role of manganese SOD on growth and invasive properties of human estrogen-independent breast cancer cells. Breast Cancer Res Treat 2008;108:203-15.

38. Nelson KK, Ranganathan AC, Mansouri J, Rodriguez AM,
Providence KM, Rutter JL, et al. Elevated sod2 activity augments matrix metalloproteinase expression: Evidence for the involvement of endogenous hydrogen peroxide in regulating metastasis. Clin Cancer Res 2003;9:424-32.

39. Reddy SP, Britto R, Vinnakota K, Aparna H, Sreepathi HK, Thota B, et al. Novel glioblastoma multiforme markers with diagnostic and prognostic value identified through transcriptome analysis. Clin Cancer Res 2008;14:2978-87.

40. Hai HU, Li LM, Li DX, Bin FY, Yu Z, Ming SX, et al. Up-regulated manganese SOD expression increase apoptosis resistance in human esophageal squamous cell carcinomas. Chin Med J 2007;120:2092-8.

41. Wong KY, Yeung BH, Wong AS. Antiapoptotic effects of mitochondrial manganese SOD in ovarian cancer cells. HKMJ Suppl 2006;12 Suppl 4:S170.

42. Kuninaka S, Ichinose Y, Koja K, Toh Y. Suppression of manganese SOD augments sensitivity to radiation, hyperthermia and doxorubicin in colon cancer cell lines by inducing apoptosis. Br J Cancer 2000;83:928-34.

43. Ghazalpour A, Bennett B, Petyuk VA, Orozco L, Hagopian R, Mungrue IN, et al. Comparative analysis of proteome and transcriptome variation in mouse. PLoS Genet 2011;7:e1001393.

44. Vogel C, Marcotte EM. Insights into the regulation of protein abundance from proteomic and transcriptomic analyses. Nat Rev Genet 2012; $13: 227-32$

45. Hardiany NS, Sadikin M, Siregar N, Wanandi SI. The suppression of manganese SOD decreased the survival of human glioblastoma multiforme T98G cells. Med J Indones 2017;26:19-25. 